\title{
Assessment of left ventricular performance and myocardial viability using quantitative radioisotope techniques
}

\author{
O. PACHINGER, E. OGRIS, P. PROBST, G. JOSKOWICS, H. SOCHOR, \\ AND F. KAINDL \\ From the Cardiological Clinic of the University of Vienna and the Institute of Nuclear Medicine, \\ Krankenhaus Lainz, Vienna, Austria
}

SUMMARY The diagnostic value of a combined radionuclide technique was compared with conventional angiocardiographic techniques in 60 patients with coronary artery disease. Quantitative ${ }^{201} \mathrm{Tl}$ myocardial imaging combined with radionuclide angiocardiography using ${ }^{99 \mathrm{~m} T \mathrm{~T}-H S A}$ provided a safe and accurate method for the assessment of left ventricular performance. The defects on the ${ }^{201} \mathrm{Tl}$ images correlated with the severity of asynergy seen on the contrast ventriculogram. Static imaging alone distinguished hypokinetic from akinetic or dyskinetic areas. However, using both tracer techniques, akinesis could be distinguished from dyskinesis. In patients with disturbed left ventricular function, cardiac transit times correlated with haemodynamic changes, and left ventricular ejection fraction was the most sensitive index. Thus, this combined radionuclide approach provides data for the evaluation of overall and regional wall function. A major advantage of this non-invasive quantitative technique is its applicability to the critically ill patient at the bedside.

Over the past decade coronary angiography and left ventriculography have become essential investigations in the assessment of patients with coronary artery disease. Recent developments of new techniques employing radioactive isotopes in the evaluation of cardiac function suggest that information, previously available only at cardiac catheterisation, can now be obtained non-invasively (Hurley et al., 1971; Gorton, 1972; Pachinger et al., 1973; Zaret et al., 1973; Felix et al., 1975; Feller and Sodd, 1975; Lebowitz et al., 1975; Strauss et al., 1975; Wackers et al., 1975; Büll et al., 1976). Radionuclide imaging still requires further assessment and verification before being accepted as an effective means of delineating the extent of myocardial disease and the level of cardiac chamber performance in patients with ischaemic heart disease. The purpose of this paper is to examine the value of a combined radionuclide approach, compared with contrast angiocardiographic techniques.

Received for publication 22 August 1977

\section{Patients and methods}

Sixty patients (average age 42 years, range 28 to 65 ) with suspected coronary artery disease were examined by both contrast angiocardiographic techniques and a combined radionuclide study using static imaging with ${ }^{201} \mathrm{Tl}$ and dynamic radionuclide angiocardiography with ${ }^{99 \mathrm{~m}} \mathrm{Tc}$-human serum albumin ( ${ }^{99} \mathrm{~m}$ Tc-HSA).

\section{RADIONUCLIDE STUDY}

Myocardial perfusion imaging was performed after an intravenous injection of $2 \mathrm{mCi}$ ionic ${ }^{201}$ thallium (thallium chloride, Duphar Co., Petten, The Netherlands) with a high resolution scintillation camera (Phogamma HP, Searle Incorporation) using a high resolution, low energy, parallel hole collimator with a 25 per cent window set symmetrically around the $80 \mathrm{keV} x$-ray peak of the element. Images were obtained in the $45^{\circ}$ right anterior oblique, anterior, $60^{\circ}$ left anterior oblique, and lateral projections, beginning with the first image 15 minutes after intravenous injection of the tracer; 
$250 \mathrm{~K}$ counts were stored for each image, and were further processed by scintigraphic analyser system $(5407 \mathrm{HP})$. The scintigrams were normalised for gamma camera field non-uniformity; correction for non-cardiac background was made by subtracting the average counts per matrix element of a representative region of interest (ROI) in the upper anterior mediastinum from the total image. A 9-point smoothing procedure was then applied. In order to allow for the effect of changing blood background during the course of the examination, the individual image was always recorded at the same time interval after the intravenous injection (right anterior oblique 15 minutes, anterior 20 minutes, left anterior oblique 25 minutes, and lateral 30 minutes, after the injection of the tracer).

The thallium images were evaluated in the following way.

(1) The location of the perfusion defect was determined and its size outlined and expressed as a percentage of the total cardiac image in each projection.

(2) The average count rates determined in areas with diminished or absent uptake of ${ }^{201} \mathrm{Tl}$ were expressed as a percentage of the average counts observed in regions with scintigraphically intact myocardium.

(3) For quantification of ${ }^{201} \mathrm{Tl}$ uptake by the myocardium the scintigrams were divided into 5 count levels expressed as a percentage of maximum uptake (0 to $20 \%, 20$ to $40 \%, 40$ to $60 \%, 60$ to $80 \%$, and 80 to $100 \%$ ). The ${ }^{201} \mathrm{Tl}$ uptake of each count level was also expressed as the percentage of myocardial counts to recorded background counts in the reference area in the upper anterior mediastinum, which was taken as representative of blood background.

After completion of the myocardial perfusion study, $15 \mathrm{mCi}{ }^{99 \mathrm{~m}} \mathrm{Tc}-\mathrm{HSA}$ were injected intravenously and, using the first bolus transit, left ventricular ejection fraction (LVEF) was computed from the usual mathematical formulae (Van Dyke et al., 1972; Weber et al., 1972; Ashburn et al., 1973). The passage of the bolus was recorded in the

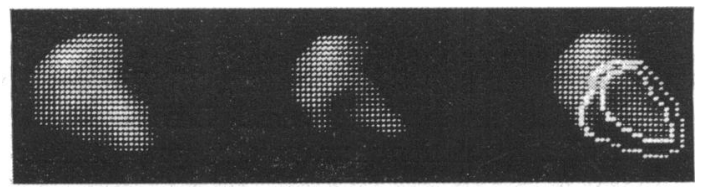

Fig. 1 Radionuclide angiography using ${ }^{99} m$ Tc-HS $A$ in a patient with normal left ventricular function. The passage of the bolus is recorded in right anterior oblique $30^{\circ}$ projection; end-diastolic and end-systolic images are outlined with a light pen and are then superimposed for the study of regional wall motion.

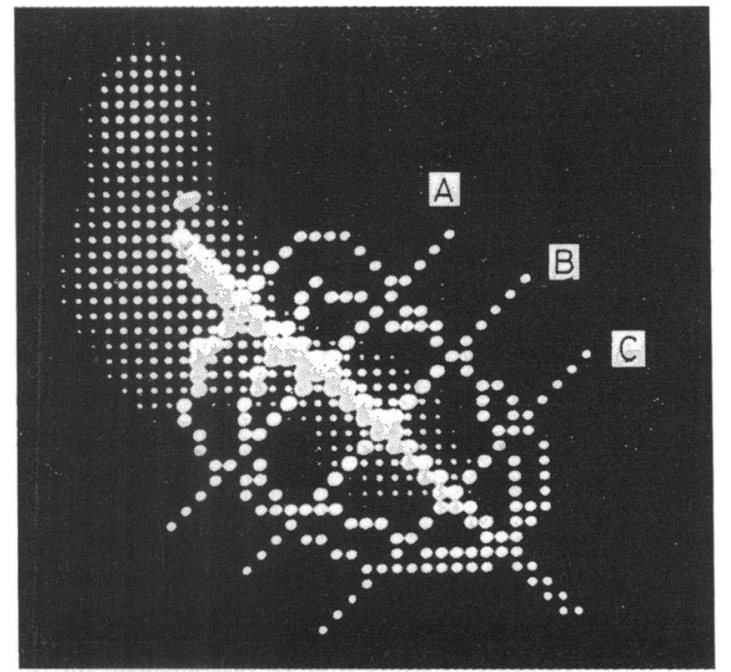

Fig. 2 Profile scanning of the end-diastolic and end-systolic images in the major length axis and in 3 axes at right-angles $(A, B, C)$ corresponding to those measured in the angiographic techniques.

$30^{\circ}$ right anterior oblique projection and stored in list mode on the magnetic disc of the scintigraphic analyser. Background correction was made from a semicircular region of interest around the apex and the anterior wall of the left ventricle (Van Dyke et al., 1972). From selected ROIs (right atrium, right ventricle, lung, and left ventricle) time activity histograms in low frequency mode (time interval 1 second) and in high frequency mode (time interval 50 milliseconds) were recorded.

Transit times (left ventricular mean transit time, pulmonary mean transit time, left ventricular minimal transit time) were calculated from the low frequency histograms after correction for recirculation. The high frequency histograms were used for the determination of LVEF after correction for the time count loss and non-cardiac background

Table 1 Data in 60 patients with 72 asynergic segments

\begin{tabular}{|c|c|c|c|}
\hline $\begin{array}{l}{ }^{201} \mathrm{Tl} \text { images } \\
\% \text { defect }\end{array}$ & $\begin{array}{l}\text { Wall motion on } \\
\text { (numbers of pa }\end{array}$ & $\begin{array}{l}n \text { contrast ventricu } \\
\text { atients) }\end{array}$ & logram \\
\hline $\begin{array}{l}\text { None } \\
0-10 \% \\
10-20 \% \\
20-30 \% \\
>30 \%\end{array}$ & $\begin{array}{l}\text { Normokinesis } \\
\text { Hypokinesis } \\
\text { Hypokinesis } \\
\text { Akinesis } \\
\text { Akinesis }\end{array}$ & $\begin{array}{l}(10) \\
(14) \\
(11) \\
(24) \text {, dyskinesis } \\
\text { hypokinesis }\end{array}$ & $\begin{array}{l}\text { (4), } \\
(3) \\
(6)\end{array}$ \\
\hline $\begin{array}{l}\text { Mean values of } \% \text { defect }^{\star} \\
18 \pm 9 \% \\
30 \pm 12 \% \\
35 \pm 9 \%\end{array}$ & $\begin{array}{l}\text { Hypokinesis } \\
\text { Akinesis } \\
\text { Dyskinesis }\end{array}$ & $\begin{array}{l}(28) \\
(34) \\
(10)\end{array}$ & \\
\hline
\end{tabular}

^ Differences between hypokinesis and akinesis or dyskinesis were significant $(P<0.01)$. 


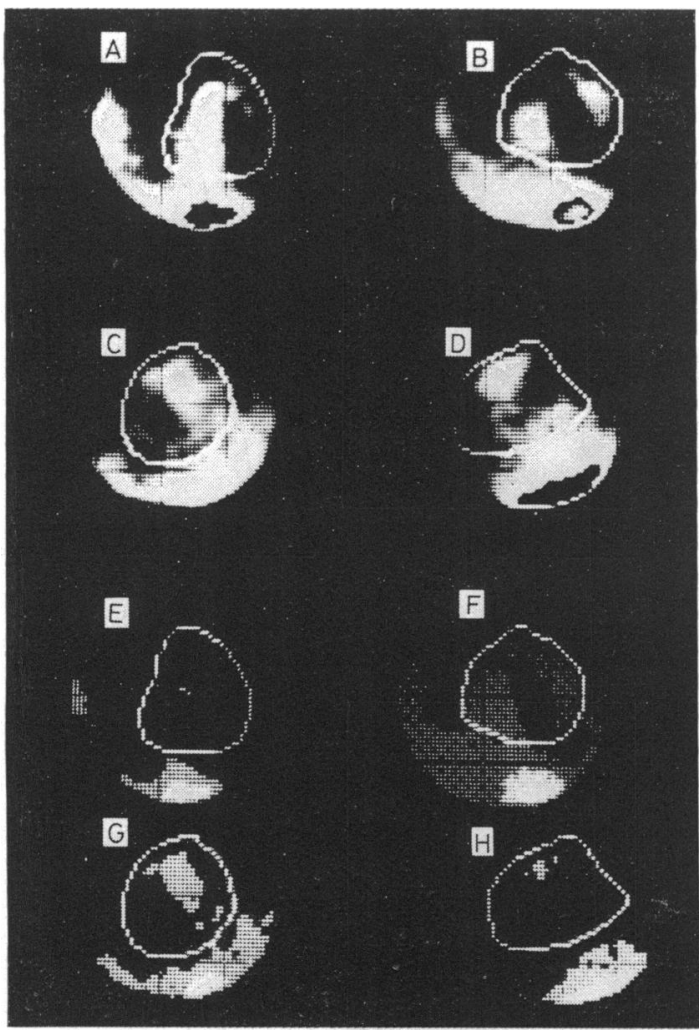

Fig. 3 Patient with anteroseptal myocardial infarction. $(A-D)$ Digitised ${ }^{201} \mathrm{Tl}$ scintigrams in right anterior oblique, anterior, left anterior oblique, and lateral views, respectively. $(E-H)$ Corresponding views displayed as 5 different count levels ( 0 to 20, 20 to 40, 40 to 60, 60 to 80 , and 80 to $100 \%$ of maximum ${ }^{201} \mathrm{Tl}$ uptake). contribution. For left ventricular wall motion analysis 4 to 6 selected end-diastolic and endsystolic frames from the early downslope part of the time activity histogram were summed up to create one representative end-diastolic and endsystolic image. These images were outlined with a light pen on the TV screen of the scintigraphic analyser and, by precise superimposition, we attempted to identify regional asynergy (Fig. 1). By subtraction of the end-systolic from the enddiastolic image, the regional distribution of stroke volume was visualised.

The ratio of the length of the end-systolic to the end-diastolic perimeter of the left ventricular circumference "was computed from both radionuclide and contrast ventriculograms to obtain

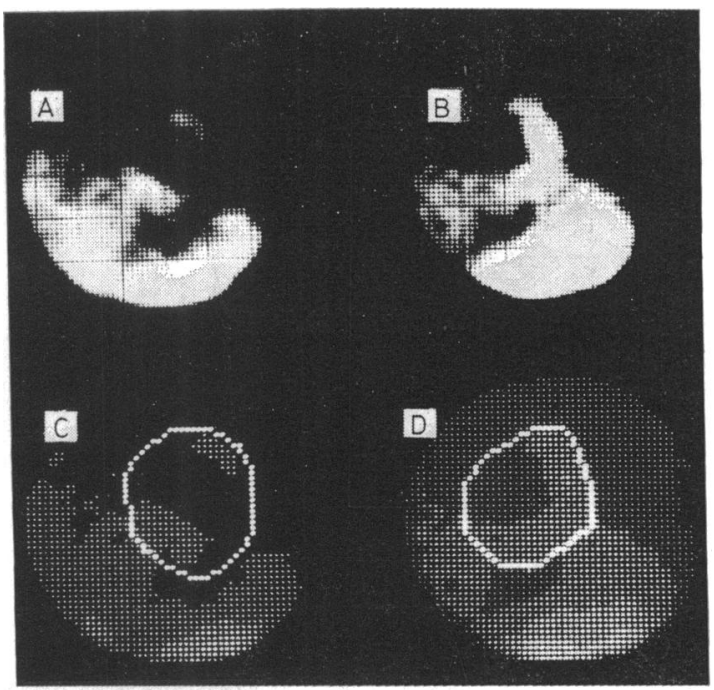

Fig. 4 Patient with extensive anteroseptal infarction. ( $A, B)$ Digitised ${ }^{201} \mathrm{Tl}$ scintigrams in the anterior and left anterior oblique projections. $(C, D)$ Five different count levels (as in Fig. 3). Note the defect in anterior wall which corresponds to 20 to 40 per cent of maximum ${ }^{201}$ Tl uptake.

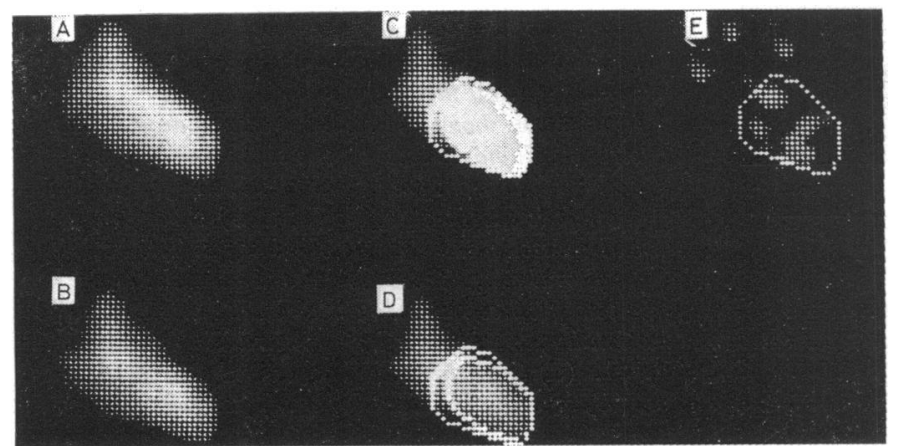

Fig. 5 Radionuclide angiography ( $R A O$ $30^{\circ}$ ) in same patient as Fig. 4 shows akinesis of anteroapical wall segments. (CD) Superimposed end-diastolic and end-systolic images. (E) Regional distribution of stroke volume. 
(a)
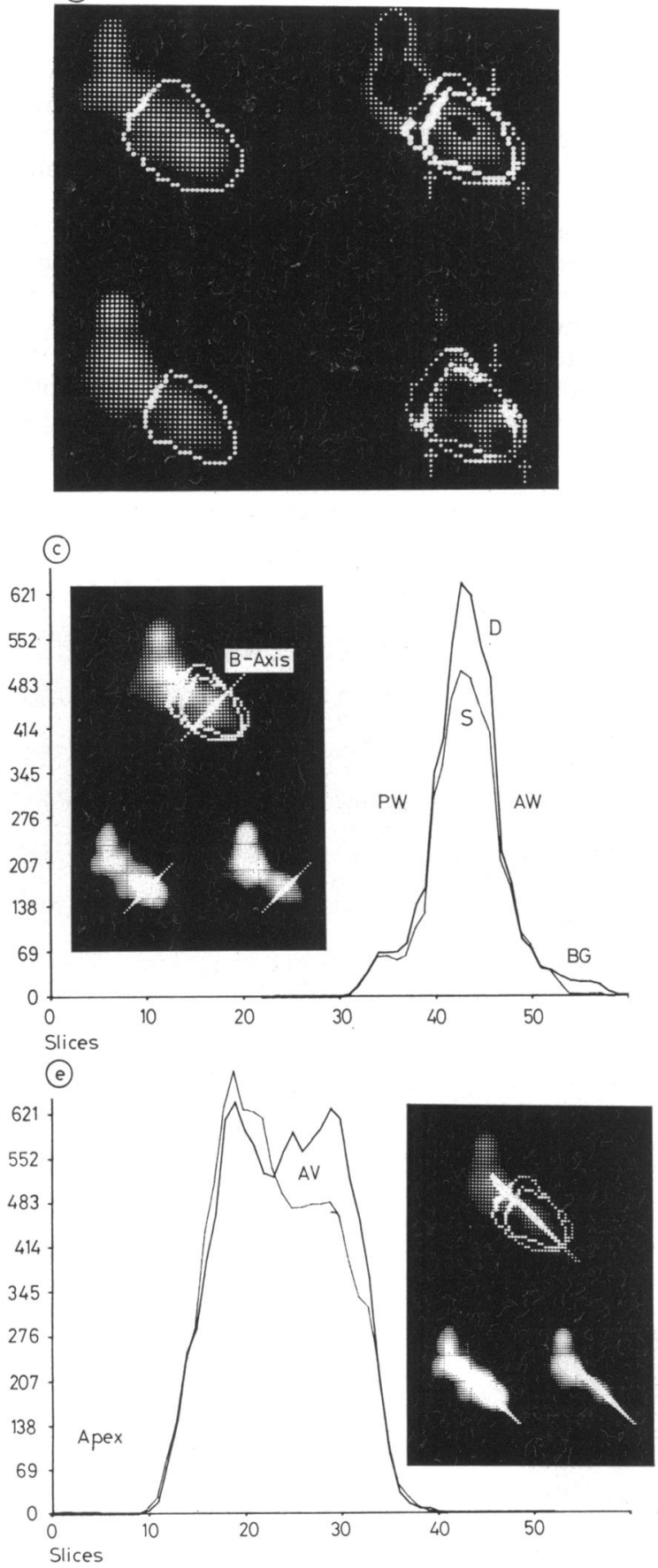

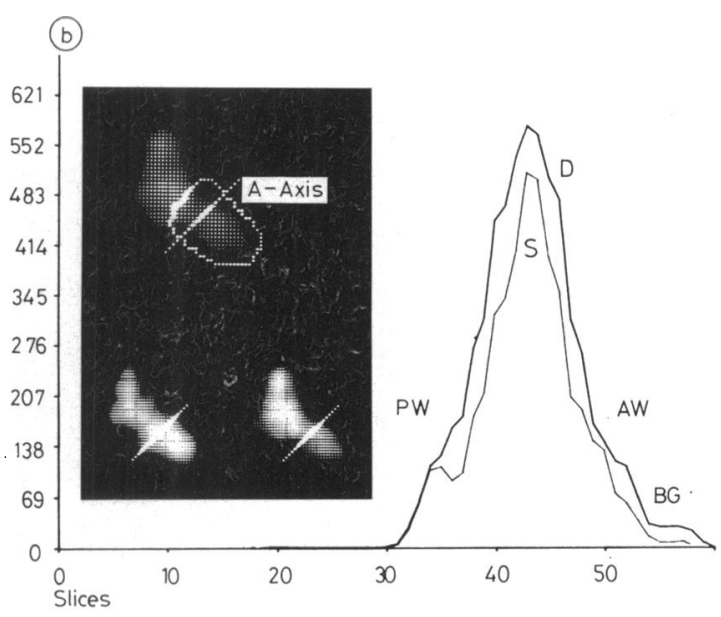

(d)

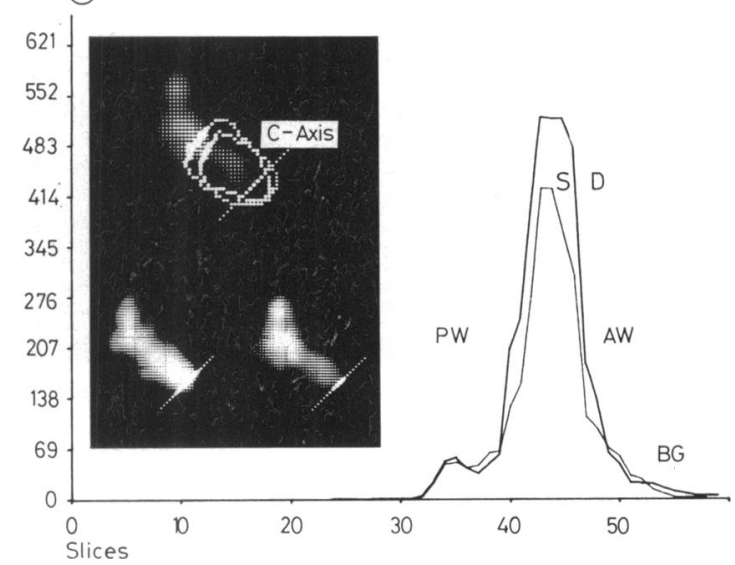

Fig. 6 The analysis of segmental wall motion from scintigram profiles: (a) On the left are shown the end-diastolic and end-systolic images of the left ventricle in the $30^{\circ}$ right anterior oblique projection. The right upper illustration shows the superimposed end-diastolic and endsystolic images (arrows point to segments with abnormal wall motion). The right lower

illustration shows the regional distribution of the stroke volume derived by the subtraction of the end-systolic from the end-diastolic image. (b) On the left is shown a profile ( $A$-axis) through the end-diastolic and end-systolic images. The activity profiles through the digitised end-diastolic and

end-systolic images are shown on the right. The good separation of the two profiles reflects normal wall motion. (c) The superimposed end-diastolic and end-systolic images show abnormal motion in the mid anterior wall and diaphragmatic segment (left). The $B$ axis profiles show akinesis in both regions (right). (d) Superimposed images and C-axis scan profiles. (e) Superimposed images and major length axis scan profiles. (S, systole; $D$, diastole; PW, posterior wall; $A W$, anterior wall; $B G$ background; $A V$, aortic valve.) 
comparable indices representative of ventricular wall motion. To analyse regional wall motion quantitatively, we obtained scan profiles from the end-diastolic and end-systolic images by measurement of the major length axis (L) and 3 axes at right-angles ( $A, B, C)$, as in the angiographic technique (Fig. 2).

HAEMODYNAMIC AND ANGIOCARDIOGRAPHIC STUDIES

Haemodynamic studies included complete right and left heart catheterisation followed by biplane
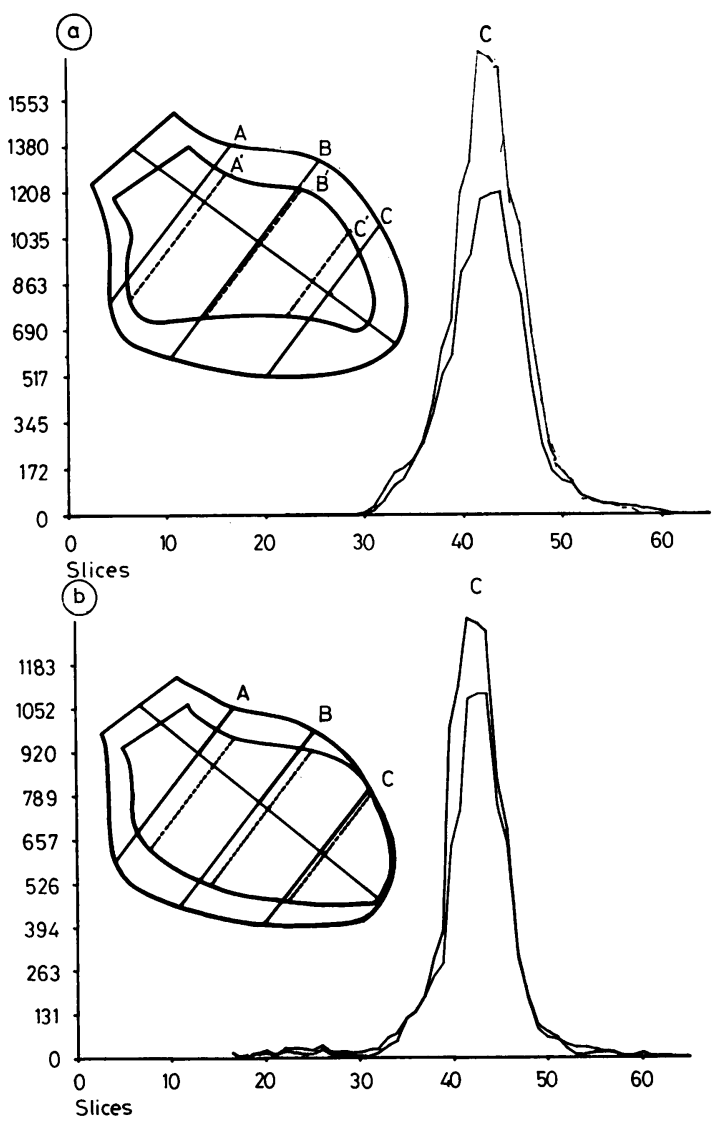

Fig. 7 Quantitative analysis of regional wall motion on contrast ventriculogram and corresponding profiles on radionuclide ventriculogram. (a) On the left are shown axes $A, B, C$ of the contrast ventriculogram; on the right, the corresponding profiles along the $C$ axis of the radionuclide ventriculogram. Both methods show good wall motion. (b) $A$ patient with akinesis of anteroapical wall segment. On the left are shown axes $A, B, C$ of the contrast ventriculogram; on the right, the lack of difference between systolic and diastolic $C$ axis profiles indicates akinesis.

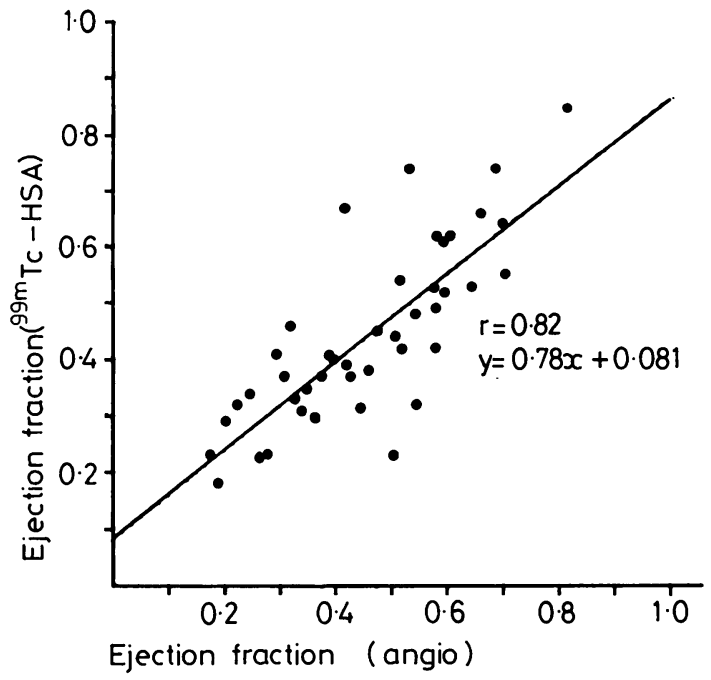

Fig. 8 Correlation between radionuclide and cineventriculographic measurement of ejection fraction in 45 patients.

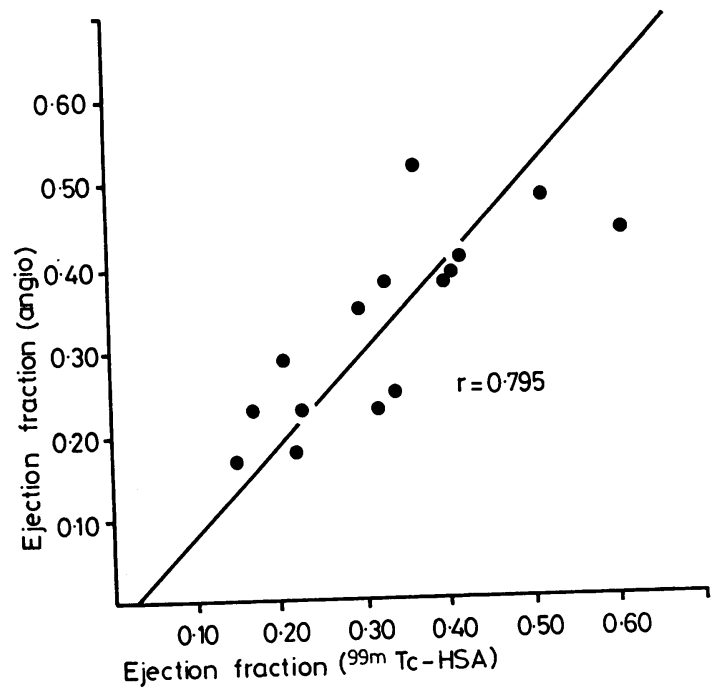

Fig. 9 Correlation between radionuclide and cineventriculographic measurement of ejection fraction in 15 patients with left ventricular aneurysm. 
cineventriculography and selective coronary arteriography. Left ventricular ejection fraction was calculated using the area-length method (Dodge et al., 1960). Regional wall motion abnormalities were analysed quantitatively by measuring the percentage systolic shortening along the 6 hemiaxes and the major length axis.

Radionuclide data were computed without knowledge of the contrast ventriculographic data. Statistical analysis used standard formulae for regression analysis and Student's paired $t$ test.

\section{Results}

The results of the analysis of ${ }^{201} \mathrm{Tl}$ images in the 60 patients are summarised in Table 1 . Ten patients showed homogeneous ${ }^{201} \mathrm{Tl}$ uptake without significant perfusion defects. All these patients showed normal wall motion on the contrast ventriculogram. In the remaining 50 patients, 72 asynergic segments were observed. Though there was some overlap, there were significant differences between the sizes of the scintigraphic defects when there were akinetic or dyskinetic areas and when there were hypokinetic zones $(P<0.01)$. However, it was not possible to separate akinetic from dyskinetic zones by static thallium imaging.

Fig. 3 shows quantitative ${ }^{201} \mathrm{Tl}$ scintigrams in a patient with anteroseptal myocardial infarction. In all patients, the location of the area with reduced ${ }^{201} \mathrm{Tl}$ uptake corresponded to abnormal wall motion on the dynamic radionuclide study. Fig. 4 shows a patient with an extensive anteroseptal myocardial infarct; the ${ }^{201} \mathrm{Tl}$ defect corresponds to anteroseptal akinesis on the radionuclide angiogram (Fig. 5).

Detailed analysis of segmental wall motion was attempted from scintigram profiles of end-diastolic and end-systolic images, as shown in Fig. 6 a-e. After superimposition, good separation of the diastolic and systolic profiles indicates normal wall motion, while a lack of difference between the two indicates akinesis; there is dyskinesis when the systolic profile exceeds the diastolic profile. The profiles were compared with the corresponding axes (A, B, C) of the contrast ventriculogram (Fig. $7 \mathrm{a}, \mathrm{b})$.

Fig. 8 shows the correlation between the ejection fraction obtained by the angiocardiographic method and that obtained by the isotope method in a group of 45 patients. None of these patients had ventricular aneurysms. In order to evaluate the sensitivity of this radionuclide technique in detecting regional dyskinesis, we examined 15 patients with angiographically proven anteroapical dyskinesis by both methods. Qualitatively, there was good agreement in 12 cases, but in 3 patients there were discrepancies. Fig. 9 illustrates the correlation between the angiocardiographic and radionuclide ejection fractions in these patients. Though the correlation is statistically significant, it is less good than in a group of patients without dyskinesis. The perimeter index (ratio of end-systolic circumference/enddiastolic circumference) was obtained by both methods; the correlation coefficient in these 15 patients was $0 \cdot 72$.

Fig. 10 shows the advantage of combining static

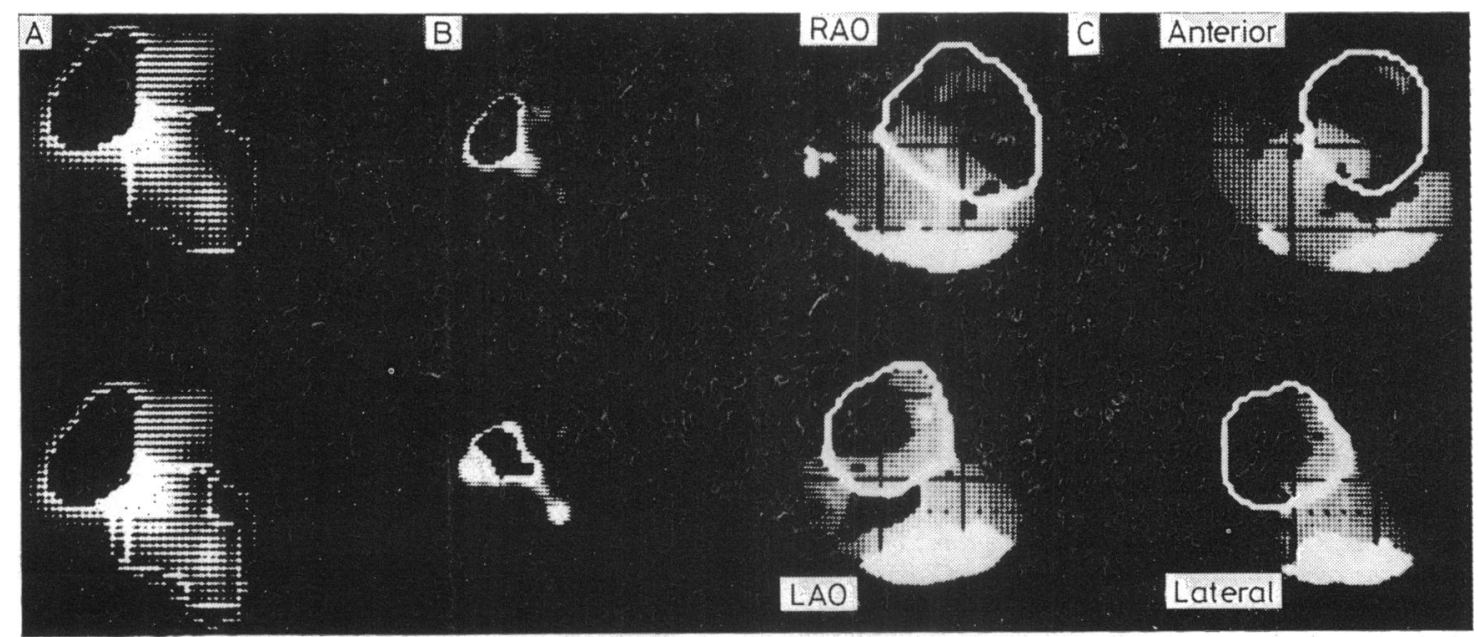

Fig. 10 Aneurysm of the anteroapical wall verified by cineventriculography. (A) The radionuclide angiocardiogram shows dyskinesis as shown by the superimposed end-systolic and end-diastolic images. (B) By raising the lowest level of counts per unit time which are displayed, stagnation of blood in the aneurysm is shown (as can be shown by cineventriculography). (C) The ${ }^{201} \mathrm{Tl}$ scan shows an anteroseptal defect. 
Table 2 Haemodynamic, angiocardiographic, and radionuclide data in patients with inferior myocardial infarction (group 1), in patients with anteroseptal myocardial infarction (group 2), and in normal control subjects

\begin{tabular}{lccc}
\hline & $\begin{array}{l}\text { Normal } \\
(n=13)\end{array}$ & $\begin{array}{l}\text { Group 1 } \\
(n=8)\end{array}$ & $\begin{array}{l}\text { Group 2 } \\
(n=14)\end{array}$ \\
\hline PA (mmHg) & $14 \cdot 0 \pm 3 \cdot 0$ & $15 \cdot 0 \pm 3 \cdot 0$ & $27 \cdot 0 \pm 12 \cdot 0^{\star}$ \\
LVEDP (mmHg) & $10 \cdot 2 \pm 2 \cdot 6$ & $14 \cdot 7 \pm 3 \cdot 2$ & $25 \cdot 2 \pm 8 \cdot 0^{\star}$ \\
EF (angio) (\%) & $63 \cdot 0 \pm 6 \cdot 0$ & $49 \cdot 0 \pm 8 \cdot 0^{\star}$ & $35 \cdot 0 \pm 12 \cdot 0^{\star}$ \\
VCF (c/s) & $1 \cdot 2 \pm 0 \cdot 2$ & $0 \cdot 9 \pm 0 \cdot 2$ & $0 \cdot 6 \pm 0 \cdot 3^{\star}$ \\
Mean TTL & $13 \cdot 9 \pm 1 \cdot 5$ & $16 \cdot 0 \pm 4 \cdot 8$ & $21 \cdot 2 \pm 7 \cdot 0^{\star}$ \\
Minimal TTLV & $5 \cdot 5 \pm 0 \cdot 9$ & $5 \cdot 6 \pm 2 \cdot 0$ & $7 \cdot 8 \pm 2 \cdot 3$ \\
Mean TTLV & $14 \cdot 9 \pm 3 \cdot 0$ & $15 \cdot 0 \pm 1 \cdot 4^{\star}$ & $21 \cdot 3 \pm 6 \cdot 0^{\star}$ \\
EF('9mTc-HSA) & $62 \cdot 0 \pm 10 \cdot 0$ & $40 \cdot 0 \pm 6 \cdot 0^{\star}$ & $37 \cdot 0 \pm 12 \cdot 0^{\star}$ \\
\hline
\end{tabular}

PA, pulmonary artery mean pressure; LVEDP, left ventricular end-diastolic pressure; EF (angio), left ventricular ejection fraction determined by cineventriculography; VCF, mean circumferential fibre shortening; Mean TTI, mean pulmonary transit time; Minimal TTLV, minimal left ventricular transit time; Mean TTLV, mean left ventricular transit time; $\mathrm{EF}\left({ }^{99} \mathrm{~m} \mathrm{Tc}-\mathrm{HSA}\right)$, left ventricular ejection fraction measured with ${ }^{\circ \mathrm{m}} \mathrm{Tc}-\mathrm{HSA}$.

$\star$ Statistically significant difference from control $(P<0.05)$.

and dynamic imaging. The perfusion defect seen on the thallium scintigram can be correlated with the functional state of this segment; if a wall motion abnormality is observed on the radionuclide angiocardiogram, the perfusion of that segment can be evaluated on the ${ }^{201} \mathrm{Tl}$ scintigram.

Haemodynamic, angiocardiographic, and radionuclide data in patients with inferior myocardial infarction (group 1), in those with anteroseptal myocardial infarction (group 2), and in normal control subjects are shown in Table 2. Haemodynamic measurements were not able to separate group 1 from the control group. However, the ejection fraction, determined by either contrast angiocardiography or by the radionuclide method, differed significantly from normal in both groups $(P<0.01)$. In patients with less severe myocardial damage, the ejection fraction was the most sensitive index of disturbed left ventricular function; in group 2, there was a significant correlation between haemodynamic and radionuclide data. The correlation coefficient ( $r$ ) between the increased pulmonary arterial pressure and the increased mean pulmonary transit time was $0.70(P<0.05)$, and the correlation between ventricular mean transit time and left ventricular end-diastolic pressure was 0.69.

\section{Discussion}

Myocardial imaging with diffusible indicators offers the prospect of non-invasive assessment of myocardial perfusion. ${ }^{201} \mathrm{Tl}$ is currently the best of these indicators because of its favourable physical and biological properties (Bradley-Moore et al., 1975;
Feller and Sodd, 1975; Lebowitz et al., 1975). The reliability and limitations of thallium scintigrams have been assessed by many authors (Strauss et al., 1975; Wackers et al., 1975; Bailey et al., 1976; Mueller et al., 1976; Pachinger et al., 1977; Wackers et al., 1976). Most of these reports deal with a qualitative correlation between ${ }^{201} \mathrm{Tl}$-imaging and conventional contrast angiocardiographic techniques. In the present study, attempts were made to measure the perfusion defects on the thallium scan and to correlate them with ventricular function. A good correlation was found between regional Tl-uptake and regional asynergy; thus, quantitative $\mathrm{Tl}$-imaging can partly indicate the severity of ventricular dysfunction. Rigo et al. (1975) and Zaret et al. (1975) showed a similar relation using potassium-43 imaging in patients with myocardial infarction. We found that the combined use of both tracer techniques, static and dynamic imaging, gives additional information about regional wall function (Pitt and Strauss, 1977).

Radionuclide angiocardiography with ${ }^{89 \mathrm{~m}} \mathrm{Tc}$ pertechnetate of $90 \mathrm{~m} \mathrm{Tc}-\mathrm{HSA}$, using a single intravenous injection of radionuclide and a scintillation camera in combination with a computer system, is an established method for the noninvasive evaluation of left ventricular function (Van Dyke et al., 1972; Weber et al., 1972; Ashburn et al., 1973). Using the first pass method, ejection fraction can be determined with an accuracy comparable with contrast angiocardiographic techniques (Ashburn et al., 1972; Steele et al., 1974). In order to obtain diagnostic information, sufficiently high count rates and a time resolution of at least 50 milliseconds per frame are necessary (Schad, 1977). Spatial resolution is a recognised limitation of the radionuclide method when compared with angiocardiographic techniques. We, therefore, determined the ratio of the end-systolic to end-diastolic length of the left ventricular circumference (perimeter index); this is a reliable angiocardiographic measurement and there was an acceptable correlation $(r=0.72)$ between measurements of this index made by the two methods. Our studies also confirm that the radionuclide technique provides a means of non-invasive diagnosis of left ventricular dyskinesis. Because of the lesser spatial resolution it is not so sensitive as contrast ventriculography. Nevertheless, 80 per cent of all dyskinetic segments were detected; this technique could thus be very useful for the diagnosis of left ventricular aneurysms in the critically ill patient in the coronary care unit.

In determining ejection fraction the radionuclide method does not suffer from the dependence on ventricular geometry encountered with the angiocardiographic and echocardiographic techniques 
(Henning et al., 1975). This independence is a major advantage for quantitative studies. Since blood radioactivity recorded from a correctly delineated left ventricle is proportional to blood volume, the time activity curve corrected for background is a measure of volume change versus time. Therefore, if the time activity curve is recorded from the entire left ventricle, quantification of left ventricular volume changes with time is possible. Contrast angiocardiography commonly tends to give higher values of ejection fraction than the radionuclide method, a difference which can be explained by methodological differences: contrast angiocardiography uses a geometrical model of the left ventricle whereas radionuclide angiocardiography provides a left ventricular volume measurement which is less dependent on the geometry of the ventricle. This difference becomes most obvious in patients with left ventricular aneurysms, where measurements of volume derived from a single plane angiocardiographic projection using a geometrical model must differ from those obtained by the integration of changes in radioactivity within the left ventricular chamber.

On the other hand, several important points have to be considered when ejection fraction is calculated from left ventricular time activity histograms. Firstly, precise fitting of the region of interest to the left ventricular silhouette is critical, especially the proper alignment of the plane of the aortic valve. Secondly, adequate count rates are necessary: we recorded count rates of between 14000 and 17000 cps within the entire field of the detector when the bolus passed through the right ventricle. Thirdly, correction for non-cardiac background activity is important: background correction was made by determining the time course of activity in a semicircular region of interest surrounding the apex and the anterior wall of the end-diastolic image. The time activity curve obtained in this way showed a pattern opposite to that of the diastolic and systolic changes of the left ventricular histogram; this was normalised for the size of the left ventricular area and then subtracted from the left ventricular time activity curve. Background correction is a very critical point of the method, since large background areas involving the aorta tend to give results which overestimate ejection fraction, compared with values obtained angiocardiographically. We have found that ejection fraction is significantly underestimated if correction for background is omitted.

There is also evidence from our results that ejection fraction might be a more sensitive indicator of disturbed left ventricular function and thus superior to other haemodynamic measurements which can be made at the bedside (pulmonary artery pressure, left ventricular end-diastolic pressure, cardiac index, etc.) in predicting mortality or identifying those patients who might develop pump failure or cardiogenic shock. Since the extent of akinesis is a reflection of infarct size, it can be considered an important prognostic indicator, and may also serve as an indicator of the effect of interventions aimed at reduction of infarct size.

In conclusion, the combined use of both radioactive tracer techniques, static ${ }^{201} \mathrm{Tl}$ imaging, and dynamic studies with ${ }^{99} \mathrm{~m}$ Tc-HSA, provides a noninvasive method for the evaluation and management of patients with coronary artery disease. The technique can be used on an outpatient basis or at the bedside; it facilitates selection of patients for cardiac catheterisation, provides information which can be used as a guide to prognosis, and can be used to assess the effect of therapeutic interventions.

\section{References}

Ashburn, W. L., Kostuk, W. H., Karliner, J. S., Peterson, K. L., and Sobel, B. E. (1973). Left ventricular volume and ejection fraction determination by radionuclide angiography. Seminars in Nuclear Medicine, 3, 165-176.

Bailey, I. K., Griffith, L. S. C., Strauss, H. W., and Pitt, B. (1976). Detection of coronary artery disease and myocardial ischemia by electrocardiography and myocardial perfusion scanning with thallium 201 (abstract). American fournal of Cardiology, 37, 118.

Bradley-Moore, P. R., Lebowitz, E., Greene, M. W., Atkins, H. L., and Ansari, A. N. (1975). Thallium-201 for medical use. II: biologic behaviour. Fournal of Nuclear Medicine, 16, 156-160.

Büll, U., Niendorf, H. P., Strauer, B. E., and Hast, B. (1976). Evaluation of myocardial function with the 201 thallium scintimetry in various diseases of the heart. European Fournal of Nuclear Medicine, 1, 125-136.

Dodge, H. T., Sandler, H., Ballew, D. W., and Lord, J. D., jun (1960). The use of biplane angiocardiography for the measurement of left ventricular volume in man. American Heart fournal, 60, 762-776.

Felix, R., Wagner, J., Pensky, W., Thurn, P., Neumann, G., Hünermann, B., Schaede, A., Simon, H., and Winkler, C. (1975). Die Myokard-Szintigraphie mit Thallium-201 als nicht-invasive Methode (in German). Deutsche medizinische Wochenschrift, 100, 2373-2377.

Feller, P. A., and Sodd, V. J. (1975). Dosimetry of four heart-imaging radionuclides: ${ }^{43} \mathrm{~K},{ }^{81} \mathrm{Rb},{ }^{129} \mathrm{Cs}$, and ${ }^{201} \mathrm{Tl}$. fournal of Nuclear Medicine, 16, 1070-1075.

Gorton, R. J. (1972). Clinical testing of ${ }^{43} \mathrm{~K}$ scans of the heart (abstract). Fournal of Nuclear Medicine, 13, 432-433.

Henning, H., Schelbert, H., Crawford, M. H., Karliner, J. S., Ashburn, W. L., and O'Rourke, R. A. (1975). Left ventricular performance assessed by radionuclide angiocardiography and echocardiography in patients with previous myocardial infarction. Circulation, 52, 1069-1075.

Hurley, P. J., Cooper, M., Reba, R. C., Poggenburg, K. J., and Wagner, H. N., jun (1971). ${ }^{43} \mathrm{KCl}$, a new radiopharmaceutical for imaging of the heart. Fournal of Nuclear Medicine, 12, 516-519.

Lebowitz, E., Greene, M. W., Fairchild, R., Bradley-Moore, P. R., Atkins, H. L., Ansari, A. N., Richards, P., and Belgrave, E. (1975). Thallium-201 for medical use. I. fournal of Nuclear Medicine, 16, 151-155. 
Mueller, T. M., Marcus, M. L., Ehrhardt, J. C., Chaudhuri, T., and Abboud, F. M. (1976). Limitations of thallium-201 myocardial perfusion scintigrams. Circulation, 54, 640-646.

Pachinger, O., Probst, P., Ogris, E., and Kaindl, F. (1977). Qantitative 201-Thallium Myocardszintigraphie bei coronarer Herzkrankheit. Herz Kreislauf, 5, 310-315.

Pachinger, O., Tillmanns, H. T., and Bing, R. J. (1973). Coronary blood flow assessment with xenon and rubidium. Seminars in Nuclear Medicine, 3, 131-138.

Pitt, B., and Strauss, H. W. (1977). Combined use of gated blood pool scan and myocardial imaging. Herz, 2, 212-214.

Rigo, P., Strauss, H. W., and Pitt, B. (1975). The combined use of gated cardiac blood pool scanning and myocardial imaging with potassium-43 in the evaluation of patients with myocardial infarction. Radiology, 115, 387-391.

Schad, N. (1977). Left ventricular wall motion after myocardial infarction (first tracer passage). Herz, 2, 210-211.

Steele, P. P., Van Dyke, D., Trow, R. S., Anger, H. O., and Davies, H. (1974). Simple and safe bedside method for serial measurement of left ventricular ejection fraction, cardiac output, and pulmonary blood volume. British Heart fournal, 36, 122-131.

Strauss, H. W., Harrison, K., Langan, J. K., Lebowitz, E., and Pitt, B. (1975). Thallium-201 for myocardial imaging: relation of thallium-201 to regional myocardial perfusion. Circulation, 51, 641-645.

Van Dyke, D., Anger, H. O., Sullivan, R. W., Vetter, W. R., Yano, Y., and Parker, H. G. (1972). Cardiac evaluation from radioisotope dynamics. Fournal of Nuclear Medicine,
13, 585-592.

Wackers, F. J. Th., Schoot, J. B. v. d., Sokole, E. B., Samson, G., Niftrik, G. J. C. v., Lie, K. I., Durrer, D., and Wellens, H. J. J. (1975). Noninvasive visualization of acute myocardial infarction in man with thallium-201. British Heart fournal, 37, 741-744.

Wackers, F. J. Th., Sokole, E. B., Samson, G., Schoot, J. B. v. d., Lie, K. I., Liem, K. L., and Wellens, H. J. J. (1976). Value and limitations of thallium-201 scintigraphy in the acute phase of myocardial infarction. New England Fournal of Medicine, 295, 1-5.

Weber, P. M., Remedios, L. V. dos, and Jasko, I. A. (1972). Quantitative radioisotopic angiocardiography. Fournal of Nuclear Medicine, 13, 815-822.

Zaret, B. L., Strauss, H. W., Martin, N. D., Wells, H. P., jun, and Flamm. M. D., jun (1973). Noninvasive regional myocardial perfusion with radioactive potassium: studies of patients at rest, with exercise and during angina pectoris. New England fournal of Medicine, 288, 809-812.

Zaret, B. L., Vlay, S. C., Freedman, G. S., Wolfson, S., and Cohen, L. S. (1975). Quantitative relationships between potassium-43 imaging and left ventricular cineangiography following myocardial infarction in man. Circulation, 52, 1076-1086.

Requests for reprints to Dr Otmar Pachinger, Cardiological Clinic of the University of Vienna, Garnisongasse 13, A-1090 Vienna, Austria. 